Research Article

\title{
Dental Caries Prevalence among 12-15 Year Old Palestinian Children
}

\author{
Maen Mahfouz and Albina Abu Esaid \\ Department of Orthodontics and Pediatric Dentistry, Dental College, Arab American University, P.O. Box 240, Jenin, Palestine \\ Correspondence should be addressed to Maen Mahfouz; maenmahfouz@gmail.com
}

Received 8 May 2014; Revised 28 June 2014; Accepted 10 July 2014; Published 1 October 2014

Academic Editor: Qi Zhang

Copyright (C) 2014 M. Mahfouz and A. Abu Esaid. This is an open access article distributed under the Creative Commons Attribution License, which permits unrestricted use, distribution, and reproduction in any medium, provided the original work is properly cited.

\begin{abstract}
Objective. To measure the distribution of dental caries in a group of Palestinian adolescents. Material and Methods. A sample of 677 individuals of both sexes ( 411 were females and 266 were males) their ages ranged from 12 to 15 year old randomly selected from schools in northern west bank in Palestine. Clinical examination was performed on all the subjects focusing on the index DMFT, representing the number of teeth that were either decayed, missing or with extraction indicated, or restored. Results. The prevalence of dental caries in the permanent dentition was $54.35 \%$ and was the highest in 15 age $75.75 \%$ in comparison to the other ages (12, 13 , and 14$)(40.57 \%, 41.76 \%$, and $60.47 \%)$, respectively. The mean DMFT for the sample was $5.39 \pm 2.85525$ while the mean DMFT for different age groups (12-15) was $5.52 \pm 2.766,5.58 \pm 2.745,5.23 \pm 3.304$, and $5.23 \pm 2.606$, respectively. The prevalence of dental caries was higher in females with DMFT $5.39 \pm 2.854$ than males with DMFT 5.26 \pm 2.891 . Conclusion. High prevalent dental caries was found among Palestinian adolescents and higher in females than males. Strict preventive programs should be implemented. Further research with large samples required to include all adolescents from Palestine.
\end{abstract}

\section{Introduction}

Dental caries is one of the most prevalent diseases afflicting human beings and persists till date as a challenge to the medical and dental profession in particular and the society in general. Information on epidemiological figures of dental caries is a fundamental requirement which updates our knowledge on changing trends of the disease, its treatment needs and helps in understanding ways and means to prevent its onset, limit its progression, and consequences [1].

Oral health is now recognized as equally important in relation to general health. The major oral health problems around the world are generally considered to be dental caries and periodontal diseases. Previous studies show that most individuals seek dental care with complaints of pain mainly because of tooth ache related to dental caries [2].

Age of 12 years has been universally accepted as global monitoring age for caries since all permanent teeth except third molars would most likely have erupted by this age. By the age of 15, the dietary habits of the individuals are more or less established and the permanent teeth have been exposed to the oral environment for 3-9 years, thus making the assessment of caries prevalence even more meaningful at this age [3]. In addition this particular age group of people from 12 to 15 year old has the longer outdoors stay at this age leading to greater consumption of inbetween meals snacks, cariogenic diet, and consequently to be considered at high risk in terms of dental caries.

Measuring dental caries prevalence among Palestinian adolescents is extremely important to establish a baseline data which is essential for oral health planners to apply intervention programs in schools.

The aim of this paper is to measure the distribution of dental caries among 12-15 year old adolescents of northern part of Palestine.

\section{Materials \& Methodology}

This study was carried out on 677 individuals of both sexes (411 were females and 266 were males); their ages ranged from 12 to 15 years. This sample was randomly selected from different schools in four main governorates in northern 
TABLE 1: Shows the percentage and number of source population whereby the samples (677) were drawn.

\begin{tabular}{lcc}
\hline Governorate & Percentage & Number \\
\hline Jenin & $45 \%$ & 305 \\
Tobass & $20 \%$ & 135 \\
Qabatia & $25 \%$ & 169 \\
Alzababdeh & $10 \%$ & 68 \\
Total & $\mathbf{1 0 0 \%}$ & $\mathbf{6 7 7}$ \\
\hline
\end{tabular}

west bank in which individuals had no previous history of receiving any specific organized preventive treatment. The schools visited in four main governorates (Jenin, Tobass, Qbatia, and Alzababdeh) were chosen according to the list of Palestinian Ministry of Education. The sample involved in this study was divided into 4 groups depending on age to be expressive about dental caries status in different age groups in adolescence.

Age of 12 years has been universally accepted as global monitoring age for caries since all permanent teeth except third molars would most likely have erupted by this age. By the age of 15, the dietary habits of the individuals are more or less established and the permanent teeth have been exposed to the oral environment for 3-9 years, thus making the assessment of caries prevalence even more meaningful at this age [3].

Adolescents were examined in their respective schools seated in ordinary chair under adequate daylight and facing away from direct sunlight with the help of plain mirrors, standardized dental probes. World Health Organization (WHO) index was used to measure the prevalence of caries activity (2013) [4].

Statistical assessment was carried out using SPSS program version 20 to do descriptive statistics like mean, standard deviation and proportion was used to describe caries prevalence.

\section{Results}

This study aimed to measure the distribution of dental caries among a group of Palestinian adolescents from 12 to 15 year old in northern part of Palestine. The sample size was 677 involving different age groups.

Table 1 shows the percentage and number of source population whereby the samples (677) were drawn. Jenin Governorate represents the highest percentage which is $45 \%$ in comparison to other governorates Tobass, Qbatia, and Alzababdeh which are 25\%,20\%, and $10 \%$, respectively.

Table 2 shows the distribution of the sample according to the source of population, age, and sex. According to the source of population the sample was randomly selected from different schools in four main governorates. Accordingly, the sample is divided into four age groups from 12 to 15 year old according to the age and the sample also was divided into groups according to the sex in which each age group has both sexes; the female group size was greater than male group size in different age groups.
Table 3 shows the prevalence of dental caries in the permanent dentition which was $54.35 \%$, as well as the prevalence of dental caries in 15 age which was the highest $75.75 \%$ in comparison to the other ages $(12,13$, and 14) $(40.57 \%$, $41.76 \%$, and $60.47 \%$ ), respectively. Table 3 shows the mean DMFT for the sample which was 5.39 (SD 2.85525) while the mean DMFT for different age groups (12-15) was 5.52 (SD 2.766), 5.58 (SD 2.745), 5.23 (SD 3.304), and 5.23 (SD 2.606), respectively.

Table 4 shows the prevalence and severity of dental caries in different age groups (12-15 year old) for females. The highest percentage of dental caries prevalence for females was found in age 15 in comparison to other age groups while the lowest percentage for females is found in age 13. The highest DMFT score in females was in the age group 13 in comparison to other age groups while the lowest DMFT score was in the age group 15.

Table 5 shows the prevalence and severity of dental caries in different age groups (12-15 year old) for males. The highest percentage of dental caries prevalence for males was found in age 15 in comparison to other age groups while the lowest percentage for males was found in age 12 . The highest DMFT score was in the age group 12 in comparison to other age groups while the lowest DMFT score was in the age group 13 (Table 5).

The prevalence of dental caries was higher in females with DMFT 5.39 (SD 2.854) than males with DMFT 5.26 (SD 2.891). The total DMFT score for all age groups was 5.39 (SD $2.85525)$ while the total of the caries prevalence of all age groups was $54.35 \%$.

\section{Discussion}

The study reported here represents the first comprehensive analysis that includes a group of adolescents from 12 to 15 year old in northern part of Palestine. Oral health is an integral part of general health in spite of the fact that it is the most neglected one. The lack of awareness, limitation of access to the dental specialist, and underestimation of the preventive measures, even among the educated class of the society, have placed Palestinian adolescents among the most disease prone nations as shown by Tables $1,2,3,4$, and 5 .

The results showed that the prevalence of dental caries in the permanent dentition was $54.35 \%$ (Table 3 ), and the prevalence of dental caries was the highest in 15 age $75.75 \%$ in comparison to the other ages $(12,13$, and 14$)(40.57 \%, 41.76 \%$, and $60.47 \%$ ), respectively. The mean DMFT was higher comparing with the global indicator of caries monitoring which 
TABLE 2: Shows the distribution of the sample according to the source of population, age, and sex.

\begin{tabular}{|c|c|c|c|c|}
\hline Age group & Governorate & Female & Male & Total \\
\hline \multirow{4}{*}{12} & Jenin & 35 & 23 & \multirow{4}{*}{175} \\
\hline & Tobass & 24 & 19 & \\
\hline & Qabatia & 29 & 18 & \\
\hline & Alzababdeh & 13 & 14 & \\
\hline \multirow{4}{*}{13} & Jenin & 24 & 21 & \multirow{4}{*}{170} \\
\hline & Tobass & 26 & 16 & \\
\hline & Qabatia & 28 & 19 & \\
\hline & Alzababdeh & 24 & 12 & \\
\hline \multirow{4}{*}{14} & Jenin & 29 & 21 & \multirow{4}{*}{167} \\
\hline & Tobass & 23 & 14 & \\
\hline & Qabatia & 28 & 19 & \\
\hline & Alzababdeh & 23 & 10 & \\
\hline \multirow{5}{*}{15} & Jenin & 42 & 18 & \multirow{4}{*}{165} \\
\hline & Tobass & 21 & 9 & \\
\hline & Qabatia & 31 & 15 & \\
\hline & Alzababdeh & 11 & 18 & \\
\hline & & 411 & 266 & 677 \\
\hline
\end{tabular}

TABLE 3: Shows the prevalence and severity of dental caries mean DMFT in different age groups (12-15 year old).

\begin{tabular}{lccccc}
\hline Age group & Total number & Affected number & Caries prevalence & DMFT (Mean \pm SD) & Number of teeth remaining \\
\hline 12 & 175 & 71 & $40.57 \%$ & $5.52 \pm 2.766$ & 3997 \\
13 & 170 & 71 & $41.76 \%$ & $5.58 \pm 2.745$ & 3929 \\
14 & 167 & 101 & $60.47 \%$ & $5.23 \pm 3.304$ & 3655 \\
15 & 165 & 368 & $75.75 \%$ & $5.23 \pm 2.606$ & 3132 \\
& 677 & & $54.35 \%$ & $5.39 \pm 2.85525$ & 14713 \\
\hline
\end{tabular}

TABLE 4: Shows the prevalence and severity of dental caries and mean DMFT in different age groups (12-15 year old) for females.

\begin{tabular}{lccccc}
\hline Age group & Total number & Affected number & Caries prevalence & DMFT (Mean \pm SD) & Number of teeth remaining \\
\hline 12 & 101 & 50 & $49.50495 \%$ & $5.28 \pm 2.167$ & 2443 \\
13 & 102 & 44 & $43.1372 \%$ & $6.05 \pm 2.803$ & 2426 \\
14 & 103 & 70 & $67.96116 \%$ & $5.31 \pm 3.500$ & 2276 \\
15 & 105 & 92 & $87.6190 \%$ & $5.21 \pm 2.654$ & 2186 \\
& 411 & 256 & $62.28 \%$ & $5.39 \pm 2.854$ & 9331 \\
\hline
\end{tabular}

TABLE 5: Shows the prevalence and severity of dental caries and mean DMFT in different age groups (12-15 year old) for males.

\begin{tabular}{lccccc}
\hline Age group & Total number & Affected number & Caries prevalence & DMFT (Mean \pm SD) & Number of teeth remaining \\
\hline 12 & 74 & 21 & $28.37837 \%$ & $6.10 \pm 3.846$ & 1554 \\
13 & 68 & 27 & $39.70588 \%$ & $4.81 \pm 2.512$ & 1501 \\
14 & 64 & 31 & $48.4375 \%$ & $5.03 \pm 2.858$ & 1378 \\
15 & 60 & 112 & $55 \%$ & $5.30 \pm 2.506$ & 946 \\
& 266 & & $42.10 \%$ & $5.26 \pm 2.891$ & 5379 \\
\hline
\end{tabular}

was 5.39 (SD 2.85525) while the mean DMFT for different age groups (12,13,14, and 15) was 5.52 (SD 2.766), 5.58 (SD 2.745), 5.23 (SD 3.304), and 5.23 (SD 2.606), respectively (Table 3).

In this study the dental caries prevalence in comparison to other studies was lesser like study done by Shingare et al. who found that caries prevalence in Indian school children in age group 11-14 was 73\% while in this study caries prevalence was different and ranged from $40.57 \%$ to $60.47 \%$ for age groups 12-14 [5] and a study done by Ahmed et al. and Rajab et al. on school children from Bagdad and Amman, respectively, found that dental caries prevalence in 12 year old age group was $62 \%, 45.5 \%$ which is different and higher 
than this study which found dental caries prevalence at age 12 group is $40.57 \%$ [6-8]. This finding is in contrast with a study done by Moses et al. who found the dental caries prevalence is $44.62 \%$ among $12-15$ age group which is lesser than this study [9-11].

In the current study the prevalence of dental caries was higher in females $62.28 \%$ than males $42.10 \%$. This finding corresponds with the study carried out by Okeigbemena who mentioned that the prevalence of dental caries in females was higher than males [7] and another study conducted by Shingare et al. found that the prevalence of dental caries in females was higher than males [5]. In contrast Moses et al. found that there was an increase in caries prevalence in boys compared to females [9].

\section{Conclusion}

(1) High prevalent dental caries was found among Palestinian adolescents from age 12 to 15 years especially in females. The reasons for this would mainly be lack of dental awareness, motivation, ignorance, poor oral hygiene, improper tooth brushing techniques, and inadequate exposure to fluorides. Other contributing factors could be improper dietary habits, longer outdoors stay of children at this age leading to greater consumption of inbetween meals snacks, cariogenic diet, and nutritional deficiencies.

(2) Different preventive measures should be applied to different ages and genders based on the findings that their caries prevalence and severity were different.

(3) Strict preventive programs should be implemented and awareness of the adolescents' personal health measures is a must.

(4) Further research and investigation with large samples required to include all adolescents from middle and southern Palestine as well as a wide group of Palestinian population.

\section{Conflict of Interests}

The authors declare that there is no conflict of interests regarding the publication of this paper.

\section{References}

[1] V. Munjal, A. Gupta, P. Kaur, and R. Garewal, "Dental caries prevalence and treatment needs in 12 and 15-year-old school children of Ludhiana city," Indian Journal of Oral Sciences, vol. 4, no. 1, pp. 27-30, 2013.

[2] L. C. Carneiro and M. N. Kabulwa, "Dental caries, and supragingival plaque and calculus among students, Tanga, Tanzania," ISRN Dentistry, vol. 2012, Article ID 245296, 6 pages, 2012.

[3] World Health Organization Oral Health Surveys, Basic Methods, 4th edition, 1997, http://www.who.int/oral_health/publications/9789241548649/en/.
[4] World Health Organization Oral Health Surveys, Basic Methods, 4th edition, 2013, http://www.paho.org/hq/dmdocuments/ 2009/OH_st_Esurv.

[5] P. Shingare, V. Jogan, S. Sevekar, S. Patil, and M. Jha, "Dental caries prevalence among 3-14yeaqr old school children, Uran, Raigad District, Mahrashtara," Journal of Contemporary Dentistry, vol. 2, no. 2, pp. 11-14, 2012.

[6] N. A. Ahmed, A. N. Åstrøm, N. Skaug, and P. E. Petersen, "Dental caries prevalence and risk factors among 12-year old schoolchildren from Baghdad, Iraq: a post-war survey, International Dental Journal, vol. 57, no. 1, pp. 36-44, 2007.

[7] S. A. Okeigbemena, "The prevalence of dental caries among 12 to 15-year-old school children in Nigeria: report of a local survey and campaign," Oral Health and Preventive Dentistry Journal, vol. 2, no. 1, pp. 27-31, 2004.

[8] L. D. Rajab, P. E. Petersen, Z. Baqain, and G. Bakaeen, "Oral health status among 6- and 12-year-old Jordanian Schoolchildren," Oral Health \& Preventive Dentistry, 2014.

[9] J. Moses, B. N. Rangeeth, and D. Gurunathan, "Prevalence of dental caries, socio-economic old school going children of chidambaram status and treatment needs among 5 to 15 year old school going children of chidambaram," Journal of Clinical and Diagnostic Research, vol. 5, no. 1, pp. 146-151, 2011.

[10] C. M. de Almeida, P. E. Petersen, S. J. André, and A. Toscano, "Changing oral health status of 6- and 12-year-old schoolchildren in Portugal," Community Dental Health, vol. 20, no. 4, pp. 211-216, 2003.

[11] H. Y. Wang, P. E. Petersen, J. Y. Bian, and B. X. Zhang, "The second national survey of oral health status of children and adults in China," International Dental Journal, vol. 52, no. 4, pp. 283-290, 2002. 


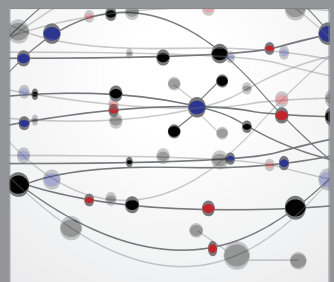

The Scientific World Journal
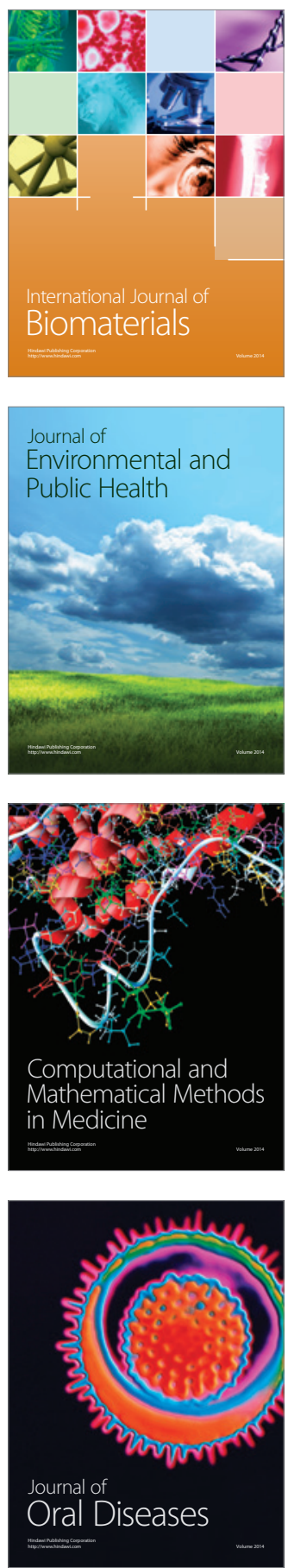
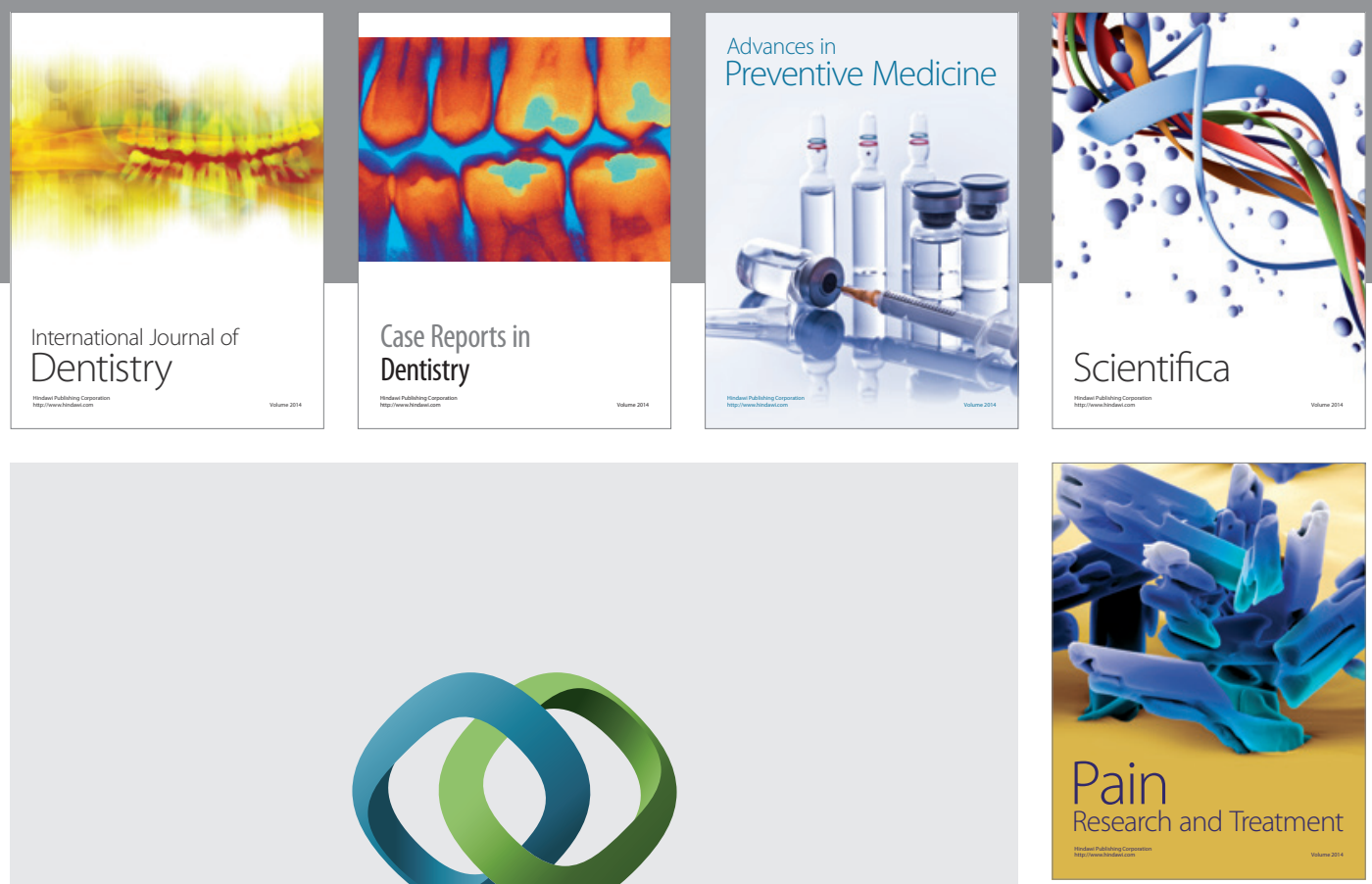

\section{Hindawi}

Submit your manuscripts at

http://www.hindawi.com
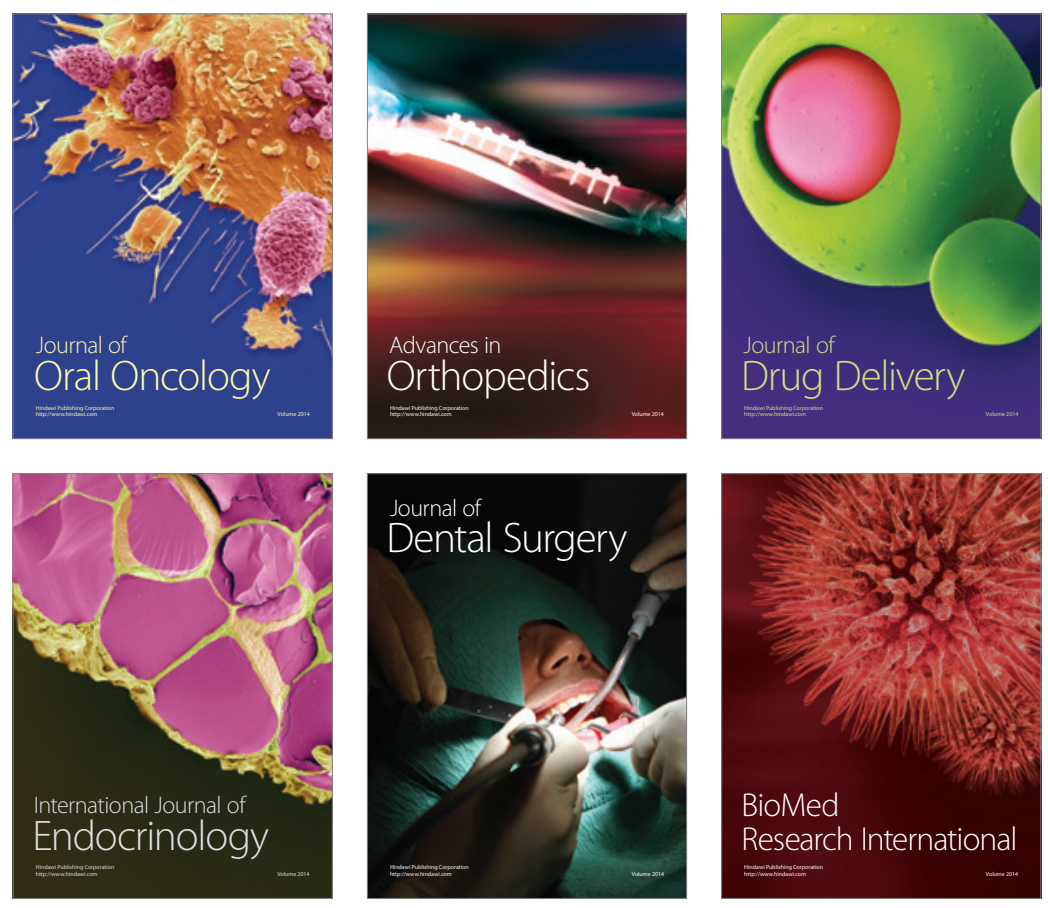

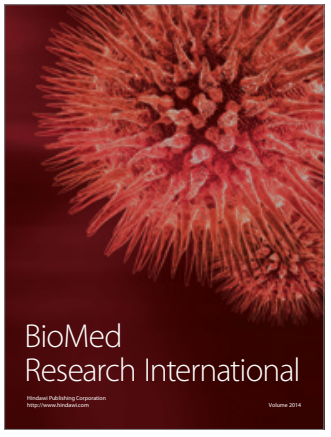

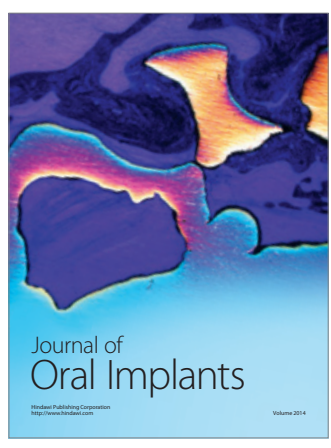
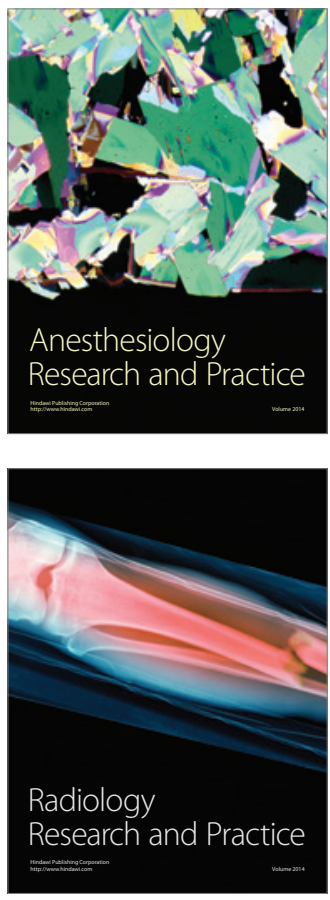